\title{
Healthy Aging in Finland: Patients Adhere Well to Chronic Statin Therapy and Their Doctors to the Guidelines
}

\author{
Editorial to: "Older Statin Initiators in Finland - Cardiovascular Risk Profiles \\ and Persistence of Use" by E. Upmeier et al.
}

\author{
Robert H. Vander Stichele • Yoleen Van Camp
}

Published online: 23 May 2014

(C) Springer Science+Business Media New York 2014

In this issue of Cardiovascular Drugs and Therapy, Upmeier et al. publish a longitudinal study of nine consecutive one-year cohorts (2000-2009) of all initiators of statin therapy, aged 70 years or more in Finland [1]. It is a fine example of the power of epidemiological resources in the Scandinavian countries [2].

In these countries with universal public health insurance, comprehensive drug databases are available that cover all reimbursed drugs for nearly the entire population. Moreover, these data on drug utilisation can be linked on the individual level with other clinical databases from hospitals, mortality registers, etc. Methodological rigor can be applied to build inception cohorts with firsttime users, using data from the preceding 3 years before the first index date. This approach allows to ascertain the absence of drug use prior to an index date to select firsttime users within a credible time-window [3].

In this study the longitudinal perspective spans 12 years (the initial drug-free window and then 9 years of observation). It is an achievement to maintain data integrity and consistency over such long periods on such a scale. Pharmaco-epidemiologists, clinical epidemiologists and public health researchers in other countries can only dream such studies, which require uniquely rich information resources.

Finland is a country with a stable population of 5.3 million inhabitants, with a death and birth rate of

R. H. Vander Stichele $(\bowtie)$

Heymans Institute of Pharmacology, University of Ghent, Ghent, Belgium

e-mail: robert.vanderstichele@ugent.be

Y. Van Camp

Centre for Research and Innovation in Care (CRIC), University of

Antwerp, Antwerp, Belgium approximately $1.5 / 1000$ inhabitants, and $19.2 \%$ of adults being 65 and older. Over the past decades, the death rate from cardiovascular disease has fallen from a high level, as in many other affluent countries in Europe, and particularly in the North of Europe [4, 5].

The data from this study indicate that the $51.6 \%$ of the statin initiators were persistent after 4 years in Finnish community-dwelling older adults from 70 years old and more (61,7 \% if a gap of one or more years was allowed). Only $20 \%$ were non-persistent in the first year. There is a steady small decline of full persistence over the 4 years, but persistence in the first year seems to predict further long-term persistence.

In this study the loss to follow up (death or institutionalisation) was $17.6 \%$ over 4 years, which is quite low in this age group, and indicative of good health, despite the cardiovascular risk profile in this age group.

Statin use in Finland in this age group predominantly occurred in middle and high cardiovascular risk patients, and only in $10 \%$ in low risk patients. Given the limitations of the methodology (insensitive to the risk factors of weight, smoking and lipid levels), this low percentage may even be an overestimation. It means that Finnish GPs follow the guidelines and largely limit the use of statins to middle and high risk patients. As the general practitioners of Finland have established a highly efficient, technologically advanced guideline platform with high penetration, this may not come as a surprise [6].

The rather low discontinuation rates among Finnish older adults are surprising, and contrast with higher rates found in 1 year adherence in ambulatory patients of all ages in several diseases. Vrijens et al. compiled adherence data from electronic monitoring and Upmeier et al. used pharmacist data [7]. Vrijens et al. found a 1 year persistence rate of $50 \%$, whereas in the present study by Upmeier et al. this figure was about $80 \%$ in the first year. Upmeier et al.'s adherence measure was restricted to statins, whereas Vrijens et al. compiled data for all 
antihypertensives. It is possible that the technique of measuring persistence used in the study by Upmeier et al. with the anniversary method (lack of dispensing in the 90 days before and after the anniversary of the index date) is inflating the results [8]. The problem with refill data is that it requires the passage of two successive refill dates, with no refill occurring, in order to be reasonably confident that the patient has discontinued dosing, i.e., persistence has ended. It is an inherent limitation of refill data that this problem prevails. The authors examined as carefully as they could this possible bias, but it could not be definitively ruled out. Their approach might be appropriate for establishing persistence over long periods. However, even the patients with "perfect" persistence (with acts of dispensing in each time period around the anniversary date of their initiation) may have substantial gaps during these 4 years and a poor implementation of their regimen, impeding the effectiveness of their treatment.

It seems, at least In Finland, that this older population of moderate and high cardiovascular risk is more persistent. This result deserves further study to understand the basis for the exceptionally long persistence found in this study.

The authors point at a doubling of the number of initiators of statin use in the group of $80 \%$. However, this is given in absolute numbers, but the population of $80+$ is rising in all countries. The debate on the effectiveness of statin therapy in the oldest old is still very little supported by evidence. Recently much attention has been given to quaternary prevention, namely actions undertaken to identify populations at risk of overtreatment and to protect them from invasive medical interventions and unsubstantiated treatment [9]. Databases may not yet contain the information that allows to ascertain whether the quality of life to come is more important than the duration of life to come.

\section{References}

1. Upmeier E, Korhonen MJ, Rikala M, Salvmivaare AH, Huupponem $\mathrm{R}$. Older statin initiators - cardiovascular risk profiles and persistence of use. Cardiovasc Drugs Ther 2014;28:this issue.

2. Furu K, Wettermark B, Andersen M, Martikainen JE, Almarsdottir AB, Sørensen HT. The Nordic countries as a cohort for pharmacoepidemiological research. Basic and Clinical Pharmacology and Toxicology. 2010;106:86-94.

3. Steiner JF, Prochazka AV. The assessment of refill compliance using pharmacy records: methods, validity, and applications. Journal of Clinical Epidemiology. 1997;50:105-16.

4. Menotti A, Puddu PE. Coronary heart disease differences across Europe: a contribution from the Seven Countries Study. Journal of Cardiovascular Medicine (Hagerstown, Md). 2013;14:767-72.

5. Vartiainen E, Laatikainen T, Peltonen M, Juolevi A, Männistö S, Sundvall J, Jousilahti P, Salomaa V, Valsta L, Puska P. Thirty-fiveyear trends in cardiovascular risk factors in Finland. Int J Epidemiol. 2010;39(2):504-18.

6. Varonen H, Jousimaa J, Helin-Salmivaara A, Kunnamo I. Electronic primary care guidelines with links to Cochrane reviews-EBM guidelines. Family Practice. 2005;22:465-9.

7. Vrijens B, Vincze G, Kristanto P, Urquhart J, Burnier M. Adherence to prescribed antihypertensive drug treatments: longitudinal study of electronically compiled dosing histories. BMJ. 2008;336:1114-7.

8. Arnet I, Abraham I, Messerli M, Hersberger KE. A method for calculating adherence to polypharmacy from dispensing data records. International Journal of Clinical Pharmacy. 2014;36:192-201.

9. Kuehlein T, Sghedoni D, Visentin G, et al. Quaternary prevention: a task of the general practitioner. Primary Care. 2010;18:350-4. 